\title{
Estudio del desarrollo embrionario del sábalo (Prochilodus lineatus)
}

\author{
Study of the embrionary development in sábalo (Prochilodus lineatus)

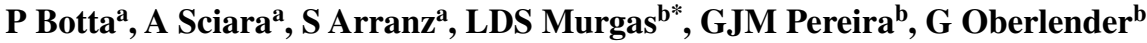 \\ anstituto de Biología Molecular y Celular de Rosario (IBR-CONICET). Universidad Nacional de Rosario, Argentina. \\ bSetor de Fisiología e Farmacología - Departamento de Medicina Veterinaria, Universidad Federal de Lavras, Lavras, Brasil.
}

\begin{abstract}
SUMMARY
Currently, the storage of fish spermatozoa through cryopreservation is widely used. Although it is of common knowledge that the process of freezing / thawing generates DNA fragmentation of spermatozoa, the consequences of this process on embryonary development are unknown. There is great interest in developing methods for in vitro fertilization for the species Prochilodus lineatus using cryopreserved semen. In this paper we study the embryonic development of this fish, to lay the groundwork for the observation of abnormalities in the development of embryos derived from criopreserved spermatozoa. The eggs produced by this species are translucent and have a large perivitelline space, are of the telolecitic type, and presented meroblastic division during the early stages of development. Although the embrionary development of Prochilodus lineatus (Sábalo) took place in less time compared with Danio rerio (Zebrafish) the embryo goes through very similar stages. During the study it was possible to observe the periods of zygote, cleavage, blastula, gastrula, segmentation and hatching of the larvae of Sábalo. The different stages of development were successfully recorded, especially those after the transition of blastula media (TBM), when the embryo begins to transcribe its own genome.
\end{abstract}

Palabras clave: Prochilodus lineatus, peces, embriones.

Key words: Prochilodus lineatus, fish, embryos.

\section{INTRODUCCIÓN}

El sábalo (Prochilodus lineatus) es un pez de la familia Prochilodontidae, iliófago, distribuido por todo el sudeste de Brasil, que migra para desovar durante el período de reproducción (Fowler 1950). Esta es una especie encontrada por toda la cuenca del Río Paraná-Paraguay y Paraíba y tiene gran importancia económica y ecológica entre las especies nativas de tamaño medio y grande.

Existen diversas especies de peces en Brasil que han sido poco exploradas y para muchas de éstas se desconoce el potencial zootécnico. Para obtener éxito en la producción acuícola se vuelve necesario el conocimiento de las características morfofisiológicas y conductuales de las especies en estudio, siendo por este motivo de vital importancia el estudio de los primeros días de vida (Pezzato 1997). El conocimiento del desarrollo embrionario de diferentes especies de peces es muy importante para el correcto manejo de los recursos pesqueros, así como para describir el hábitat de los peces y disponer de información sobre su ciclo vital.

El desarrollo embrionario en peces es un complejo fenómeno, utilizado para estudios ontogénicos, modelos experimentales y evaluaciones acerca de las cualidades y efectos de substancias tóxicas en al ambiente acuático

Aceptado: 01.12.2009.

* Caixa Postal 3037, CEP 37200.000, Brasil; 1smurgas@ufla.br
(Ninhaus-Silveira y col 2006). En Brasil existen pocos estudios acerca del desarrollo embrionario del sábalo (Prochilodus lineatus). La descripción del desarrollo embrionario puede tener innumerables ventajas, como favorecer el reconocimiento de los embriones en sus ambientes naturales, permitiendo una mejor evaluación del sitio de desove de los peces y estudios relativos al crecimiento de la especie en su ambiente natural; también es importante para la detección de las alteraciones relacionadas con los factores ambientales en las incubadoras, que pueden llevar a una malformación de las larvas y consecuentemente una menor productividad (Alves y Moura 1992). Las investigaciones relativas al desarrollo embrionario y larval en peces en cautiverio han sido realizadas principalmente en especies de interés comercial (Luz y col 2001, Romagosa y col 2001).

La criopreservación es una técnica muy utilizada en el almacenamiento de espermatozoides de peces de agua dulce (Cabrita y col 2005). Los parámetros más utilizados para evaluar daños por congelamiento en el espermatozoide son la motilidad y la tasa de fecundación. Estos parámetros no proveen información sobre la integridad del ADN postdescongelamiento. Estudios recientes muestran que la criopreservación del semen de peces provoca la fragmentación del ADN. Sin embargo, hasta el momento no hay informes sobre las consecuencias de dicha fragmentación en el desarrollo embrionario. La transcripción del genoma embrionario comienza en peces al final del estadío de blástula, 
durante la transición de la blástula media. Por lo tanto, el efecto de la fragmentación del ADN sobre el desarrollo y la viabilidad de los embriones debe ser enfocado a la observación de los mismos a partir de esta etapa (Zilli y col 2003). Prochilodus lineatus (sábalo) es un pez que se encuentra distribuido a lo largo de la cuenca de los ríos Paraguay, Paraíba y Paraná, y posee una gran importancia ecológica y comercial. Como consecuencia de las diferentes actividades comerciales en dichas regiones, su número se vio drásticamente disminuido y es por ello que las técnicas de fecundación in vitro son de gran importancia para la supervivencia de dicha especie. Dentro de esta metodología, el congelamiento de semen presenta una alternativa a la manipulación de los peces reproductores en el período de reproducción. El objetivo de este trabajo fue realizar un estudio detallado del desarrollo de embriones de sábalo, desde la fecundación hasta la eclosión de los mismos, con el fin de generar un registro que posteriormente nos permita evaluar los efectos de la utilización de semen criocongelado y las consecuencias que la fragmentación del ADN produce sobre el desarrollo embrionario.

\section{MATERIAL Y MÉTODOS}

Los embriones se obtuvieron de individuos de Prochilodus lineatus, a partir del stock de peces del laboratorio de reproducción de la usina hidroeléctrica de FURNAS, en la ciudad de Passos, Estado de Minas Gerais, Brasil. Esta especie no puede reproducirse en cautiverio, por lo cual se realizó una inducción hormonal inyectando por vía intramuscular dos hembras de 4 años de edad y dos machos de tres años de edad con extracto de hipófisis de carpa (EPC), siendo compuesto de glándulas hipófisis enteras liofilizadas diluidas en solución fisiológica 0,9\%, manufacturadas en Hungría con el nombre ECP e importadas al Brasil. Los reproductores fueron mantenidos en tanques con capacidad de aproximadamente 1.000 litros de agua, con corriente y aireación constante y temperatura a $25^{\circ} \mathrm{C}$; cada individuo se inyectó dos veces, la primera inoculación con $0,5 \mathrm{mg} / \mathrm{kg}$ de peso corporal, y la segunda a las $12 \mathrm{~h}$ después con $5 \mathrm{mg} / \mathrm{kg}$ de peso corporal. La extrusión de huevos y esperma se llevó a cabo 8 h después de la segunda aplicación hormonal. El proceso de fecundación se llevó a cabo mezclando el esperma con los ovocitos, luego se adicionó agua para activar los espermatozoides y se permitió la hidratación de los huevos. Posteriormente se lavó el exceso de espermatozoides y los huevos se depositaron hasta su eclosión en incubadoras verticales de $200 \mathrm{~L}$ a $25^{\circ} \mathrm{C}$, conectadas a un sistema cerrado de agua. Para la observación del desarrollo embrionario las muestras de los huevos fueron colectadas en intervalos de 10 minutos hasta la eclosión de los huevos y observadas con una lupa; las fases más características del desarrollo embrionario fueron fotografiadas.

\section{RESULTADOS Y DISCUSIÓN}

Los huevos producidos por esta especie son translúcidos. Luego de la fecundación e hidratación, presentan un espacio perivitelino que fácilmente duplica en diámetro al embrión en desarrollo; son del tipo telolecítico, ya que acumulan vitelo en el polo vegetal de los mismos y presentan una división parcial o meroblástica durante los primeros estadíos del desarrollo (Ninhaus-Silveira y col 2006). De acuerdo con Kimmel y col (1996) el desarrollo del embrión de sábalo presenta una gran similitud con los distintos períodos del desarrollo de Danio rerio, especie descrita por Hamilton (1822). El tiempo transcurrido desde la fecundación hasta la eclosión fue de $18 \mathrm{~h}$ a $25^{\circ} \mathrm{C}$. Durante este tiempo el embrión atravesó por los siguientes períodos: Cigoto, Clivaje, Blástula, Gástrula, Segmentación y Eclosión.

\section{PERÍODO DE CIGOTO}

Este estadío se observó a los 10 minutos postfecundación (mpf). En ese período de tiempo se produjo la segregación del blastodisco diferenciando un polo animal y uno vegetal en el cigoto (figura 1). Al mismo tiempo se produjo la hidratación del huevo, y el aumento del espacio perivitelino.

\section{PERÍODO DE CLIVAJE}

El período de clivaje abarca las primeras seis divisiones, hasta que el embrión presenta 64 células. En nuestro estudio este período abarcó 1,33 horas del desarrollo

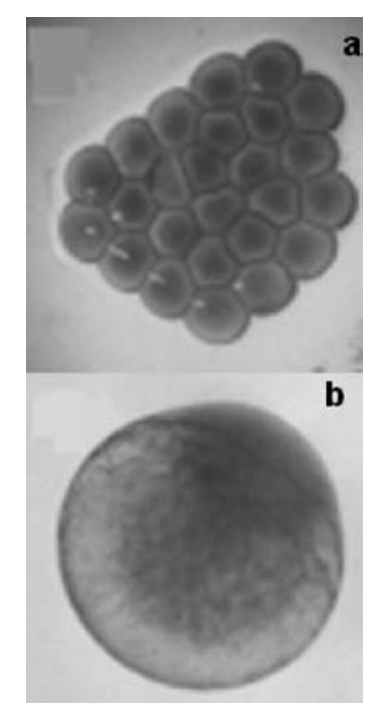

Figura 1. Estadío de Cigoto. a) Huevos de Prochilodus lineatus sin activar; b) Cigoto, estadío de 1 célula, 10 mpf (minutos postfecundación).

Zygote stadium. a) Eggs of Prochilodus lineatus without activating; b) Zygote, 1 cell stage, $10 \mathrm{mpf}$ (minutes post-fertilization). 
embrionario. Esta etapa se caracteriza por una serie de divisiones rápidas que llevan a un aumento en el número de blastómeras y a una disminución del tamaño de las mismas (Gilbert 1991). En la figura 2 se puede observar que el clivaje de las primeras divisiones celulares se lleva a cabo de la siguiente forma: el primer ciclo de división celular se da en un plano de clivaje vertical, dando lugar a dos blastómeras; en el segundo ciclo el plano de división fue vertical y perpendicular al primero, dando lugar a 4 blastómeras en una disposición $2 \times 2$; en el tercer ciclo la división celular se da en dos planos verticales y paralelos al plano del primer ciclo de división, dando lugar a ocho blastómeras en una disposición de 2x4; en el cuarto ciclo la división se da en cuatro planos verticales y paralelos al plano de la segunda división, esto da lugar a dieciséis células en una disposición de 4x4. La última división de este período se realiza en un plano horizontal y genera 64 células que se distribuyen en dos capas de células, cada una de ellas ubicada una sobre la otra en el blastodisco.

\section{PERÍODO DE BLÁSTULA}

Durante este período el blastodisco adopta una forma esférica característica. El período de blástula abarcó

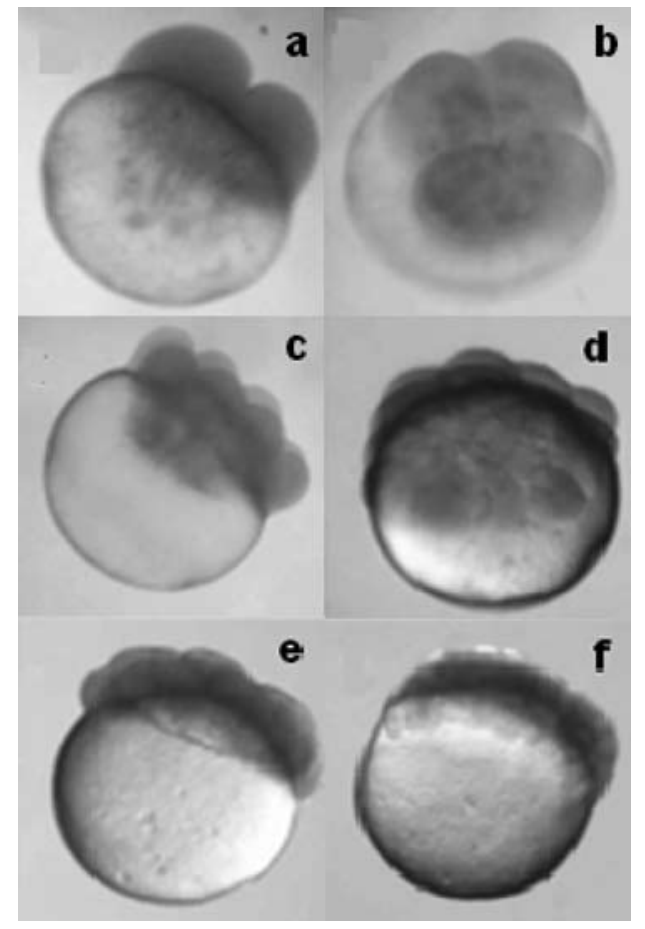

Figura 2. Estadios del período de Clivaje. a) 2 células, $20 \mathrm{mpf}$ (minuto postfecundación); b) 4 células, $35 \mathrm{mpf}$; c) 8 células, 50 mpf ; d) 16 células, 1 hpf (horas postfecundación); e) 32 células, 1,25 hpf; f) 64 células, 1,5 hpf.

Stages of the Cleavage period. a) 2 cells, $20 \mathrm{mpf}$ (minutes post-fertilization); b) 4 cells, $35 \mathrm{mpf}$; c) 8 cells, $50 \mathrm{mpf}$; d) 16 cells, $1 \mathrm{hpf}$ (hours post-fertilization); e) 32 cells, $1.25 \mathrm{hpf}$; f) 64 cells, $1.5 \mathrm{hpf}$.
3 horas, desde el estadío de 128 células hasta la formación del anillo germinal en el embrión (que indica el inicio de la gastrulación). A medida que se avanza en este período se produce la transición de la blástula media (TBM), donde el embrión inicia la transcripción de su genoma; se forma la capa vitelina sincitial (CVS) y comienzan los movimientos de epibolia que luego continúan en la gastrulación (Kimmel y col 1995).

A partir de la figura 3 se puede apreciar un embrión que ha atravesado el estadío de 512 células. Se ha descrito que el estadío de 512 células es de particular importancia ya que se forma la capa vitelina sincitial y comienza la TBM (Gilbert 1991). En la figura 3b se observa el estadío de Elevación (High, en inglés); durante este estadío el eje imaginario vegetal-animal llega a un máximo y se puede

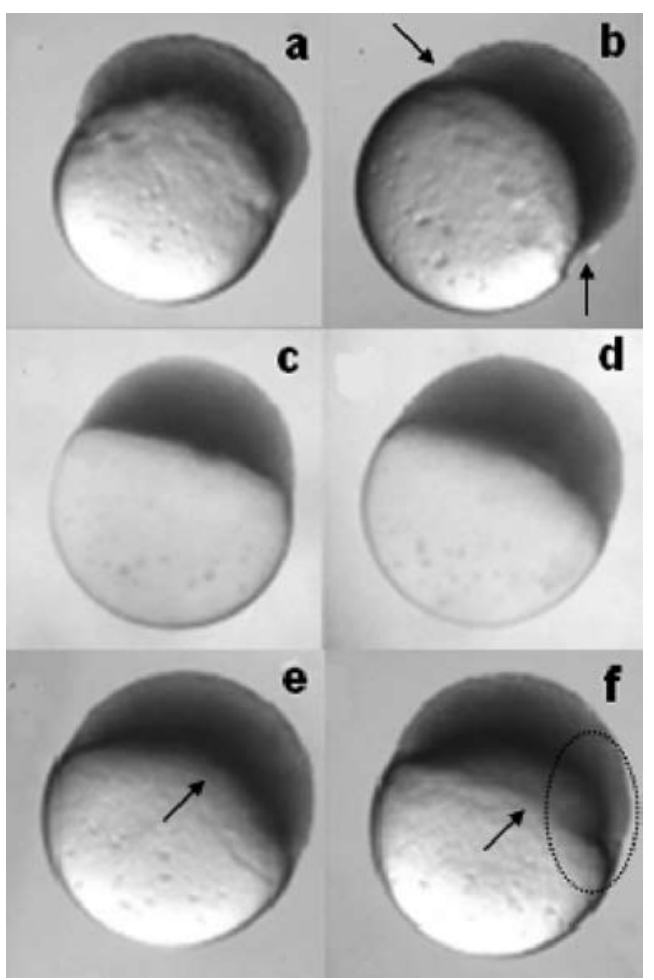

Figura 3. Estadios del período de Blástula. a) 128 células, 1,83 hpf (horas postfecundación); b) estadío Alto, 2,6 hpf, las flechas indican la constricción en la CVS; c) estadío de transición Alto-Ovoide, 3,16 hpf ; d) estadío de transición Ovoide-Esfera, 3,66 hpf; e) Domo, 4,16 hpf, la flecha indica el movimiento en dirección vegetal-animal de la CVS; f) Domo, 4,5 hpf, flecha indica el movimiento en dirección vegetal-animal de la CVS, el círculo encierra la zona asimétrica que se encuentra en el domo de la CVS.

Stages of the Blastula period. a) 128 cells, $1.83 \mathrm{hpf}$ (hours post-fertilization); b) high stage, $2.6 \mathrm{hpf}$, the arrows indicate constriction in CVS; c) stage of transition High-Ovoid, $3.16 \mathrm{hpf}$; d) stage of transition Ovoid-Sphere, $3.66 \mathrm{hpf}$; e) Domo, $4.16 \mathrm{hpf}$, the arrow indicate the movement in direction of the plant-animal of the CVS; f) Domo, $4.5 \mathrm{hpf}$, the arrow indicate the movement in direction of the plant-animal of the CVS, the circle encloses the area which is asymmetric in the dome of the CVS. 
observar una constricción en el blastodermo en el sitio donde se encuentra la CVS (flecha). En el estadío Ovoide (Oblong), el eje animal-vegetal comienza a disminuir su tamaño y la blástula adquiere una forma levemente elipsoidal. Las figuras $3 \mathrm{c}$ y $3 \mathrm{~d}$ muestran estadíos de transición Elevación-Ovoide y Ovoide-Esfera, donde el eje vegetal-animal se está reduciendo, y donde la blástula adquirirá finalmente una forma esférica. Las figuras $3 \mathrm{e}$ y 3f muestran estadíos de Domo, donde ha comenzado la epibolia. En ellas se puede observar el movimiento de la CVS en sentido vegetal-animal (flechas). Este movimiento continuará en los estadíos siguientes y provocará el desplazamiento del blastodermo sobre la célula vitelina. Es de destacar la asimetría que se puede observar en el domo de la célula vitelina de la figura 3 f (círculo), lo cual no se observó que estuviera descrito en el período de blástula del desarrollo de otros peces.

\section{PERÍODO DE GÁSTRULA}

Durante este estadío el movimiento de epibolia continúa, pero a él se suman los movimientos morfogenéticos de involución, convergencia y extensión, que llevan finalmente a la generación de las diferentes capas germinales y los ejes embrionarios. Las imágenes abarcan un período de tiempo de 2,5 horas. La figura 4a muestra el comienzo de la gastrulación en el estadío de Anillo Germinal donde se observa claramente el anillo producido por la involución de las células del epiblasto (flecha). En la figura 4 b se puede observar el escudo embrionario originado como consecuencia del movimiento celular de convergencia. En la figura 4c ya puede diferenciarse el eje dorsoventral del embrión, teniendo el lado dorsal del blastodermo un mayor espesor que el ventral. También puede verse la Zona de Evacuación en el lado ventral (flecha inferior) que se produce por una migración celular hacia el lado dorsal del epiblasto, donde se generará la placa neural (flecha superior) (Kimmel y col 1995), lo cual indica la formación del eje anteroposterior del embrión.

\section{PERÍODO DE SEGMENTACIÓN Y ORGANOGÉNESIS}

Esta etapa del desarrollo abarcó unas 10 h. Durante el transcurso de este período se forma el tubo neural, y a medida que avanza el desarrollo se pueden identificar el proencéfalo (telencéfalo y diencéfalo), el mesencéfalo y el romboencéfalo; se desarrollan los somitos y se hacen visibles los rudimentos de los órganos primarios, el primordio de la cola aumenta su tamaño, se produce la elongación del embrión y se producen las primeras diferenciaciones morfológicas y los primeros movimientos corporales.

La figura 5a muestra la aparición de los primeros somitos y se destaca en la región posterior del embrión una forma similar a un botón (flecha) que se podría deber a que todavía no ha terminado la gastrulación a pesar de que se ha dado inicio a la somitogénesis. Esta característica ya se ha observado durante el desarrollo embrionario de Orechromis niloticus (Morrison y col 2001), pero se deberán hacer más estudios para confirmar estas observaciones.

En la figura 5 b se puede observar claramente la aparición de la vesícula óptica en el extremo anterior del embrión. En la figura 5c se puede observar la aparición de un primordio de la vesícula óptica, y una clara protuberancia en el extremo anterior, que corresponde al desarrollo del telencéfalo. La figura 5c muestra la aparición de la vesícula de Kuppfer (flecha), que es una estructura transitoria que sólo aparece en el desarrollo de los teleósteos durante el período de segmentación. También se puede observar el desarrollo del mesencéfalo, que forma una protuberancia en la región dorsal del extremo anterior del embrión (flecha). La figura $5 f$ muestra la desaparición de la vesícula de Kuppfer, y la aparición de la cola del embrión. En la figura $5 \mathrm{~g}$ se puede ver el embrión en un estadío de desarrollo más avanzado

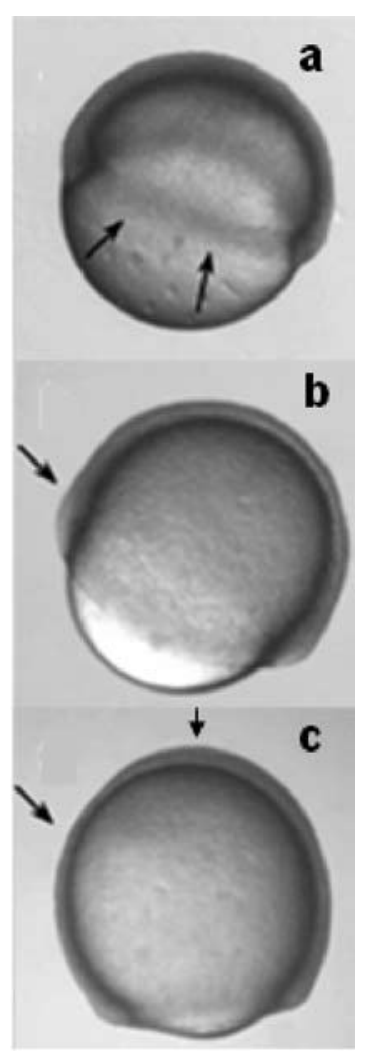

Figura 4. Estadios del período de Gástrula. a) $50 \%$ epibolia, 5,5 hpf (horas postfecundación), las flechas indican el anillo embrionario; b) 70\% epibolia, 6,5 hpf; la flecha indica el sitio de formación del escudo embrionario; c) $90 \%$ epibolia, $7 \mathrm{hpf}$, la flecha inferior señala la zona de evacuación y la superior el sitio donde se generará la placa neural.

Stages of the Gastrula period. a) $50 \%$ epibolia, $5.5 \mathrm{hpf}$ (hours post-fertilization), the arrows indicate ring embrionary; b) $70 \%$ epibolia, $6.5 \mathrm{hpf}$; the arrow indicate the site of formation of the shield embrionary; c) $90 \%$ epibolia, $7 \mathrm{hpf}$, the arrows below indicate the evacuation zone and the higher the site will generate the neural plate. 


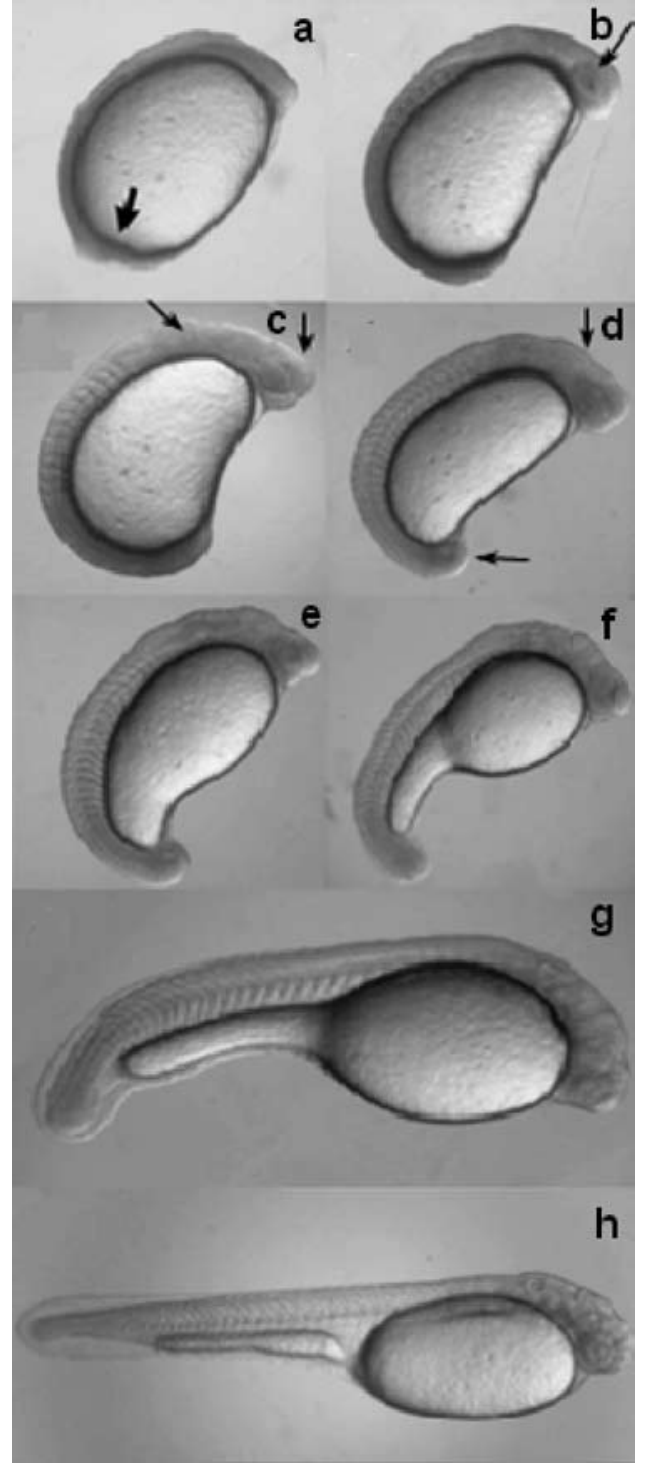

Figura 5. Estadios del período de segmentación. a) 3 somitos $8,75 \mathrm{hpf}$ (horas postfecundación); b) 8 somitos, 9 hpf; c) 13 somitos, $10 \mathrm{hpf}$; d) 18 somitos, $12 \mathrm{hpf}$; e) 20 somitos, $13 \mathrm{hpf}$;) 23 somitos, 14 hpf; g) movimiento muscular; 17 hpf.; h) larva, 18 hpf.

Stages of the period of segmentation. a) 3 somites $8.75 \mathrm{hpf}$ (hours post-fertilization); b) 8 somites, $9 \mathrm{hpf}$; c) 13 somites, $10 \mathrm{hpf;}$ d) 18 somites, 12 hpf; e) 20 somites, 13 hpf; f) 23 somites, 14 hpf; g) Muscle movement; 17 hpf.; h) larvae, 18 hpf.

donde presenta movimiento dentro del corion (primeras contracciones musculares originadas por el desarrollo de las inervaciones de las células neuromotoras). Finalmente, en la figura $5 \mathrm{~h}$ se muestra el embrión ya eclosionado, donde es de destacar la ausencia de pigmentación.

En el presente estudio se observaron los distintos estadíos del desarrollo de Prochilodus lineatus e identificar los períodos de Cigoto, Clivaje, Blástula, Gástrula, Segmentación y Eclosión. Se puso especial énfasis en la observación de los estadíos posteriores al período de Blástula, ya que durante el mismo comienza la transcripción del genoma embrionario. El desarrollo embrionario de esta especie presentó un patrón similar al descrito en Danio rerio; sin embargo se encontraron algunas particularidades como la que se observa en la figura $3 \mathrm{e}$, donde se puede ver que hay una asimetría en el embrión en estadío de Domo. Si bien esta asimetría también puede ser observada en el desarrollo de Danio rerio, esto sucede luego de la formación del anillo germinal en el sitio de formación del escudo embrionario (Kimmel y col 1995). A diferencia de esto, el sábalo presenta dicha asimetría antes de la formación del escudo embrionario. Otra particularidad que se encontró en el desarrollo de Prochilodus lineatus es que el comienzo de la somitogenésis se da antes de que el blastodermo cubra totalmente la célula vitelina, lo cual ya ha sido descrito en el desarrollo de otras especies de teleósteos.

Los resultados obtenidos permiten concluir que el desarrollo embrionario del sábalo en las condiciones del estudio ha llevado un tiempo de 18 horas desde la fecundación hasta la formación de la larva. La presente investigación servirá como referencia para estudios posteriores, donde se evaluarán los efectos de la crioconservación de espermatozoides de peces sobre el genoma de los mismos, y su posible efecto en el desarrollo de los embriones obtenidos a partir de ellos, tanto a nivel de detención del desarrollo como sobre la formación de las estructuras embrionarias.

\section{RESUMEN}

El almacenamiento de espermatozoides de peces por medio de la criopreservación es muy utilizado hoy en día. Si bien se sabe que el proceso de congelamiento/descongelamiento genera la fragmentación del ADN del espermatozoide, no se conocen las consecuencias que esto tiene en el desarrollo embrionario. Actualmente hay un gran interés en el desarrollo de métodos de fecundación in vitro para la especie Prochilodus lineatus utilizando semen criopreservado. En este trabajo estudiamos el desarrollo embrionario de esta especie, a fin de sentar las bases para la observación de anormalidades en el desarrollo de embriones obtenidos a partir de espermatozoides crioconservados. Los huevos producidos por esta especie son translúcidos y poseen un gran espacio perivitelino; son del tipo telolecítico y presentan una división meroblástica durante los primeros estadíos del desarrollo. Si bien el desarrollo embrionario de Prochilodus lineatus (sábalo) se llevó a cabo en menor tiempo en comparación con Danio rerio, las etapas que atravesó el embrión son muy similares. Durante el estudio se observaron los períodos de Cigoto, Clivaje, Blástula, Gástrula, Segmentación y Eclosión de la larva de sábalo. De esta manera se logró registrar los diferentes estadíos de su desarrollo, principalmente aquellos posteriores a la transición de la blástula media (TBM), a partir del cual el embrión comienza a transcribir su propio genoma.

\section{AGRADECIMIENTOS}

A Furnas Centrales Eléctricas y Compañía Energética del Estado de Minas Gerais (CEMIG) por la colaboración en la ejecución de este estudio. 


\section{REFERENCIAS}

Alves MSD, A Moura. 1992. Estádios de desenvolvimento embrionário de curimatã-pioa Prochilodus affinis (Reinhardt, 1874) (Pisces, Prochilodontidae). In: Encontro anual de aquicultura de Minas Gerais, 10, Belo Horizonte, Brasil. Três Marias: CODEVASF, Pp 61-71.

Cabrita E, V Robles, L Rebordinos, C Sarasquete, MP Herráez. 2005. Evaluation of DNA damage in rainbow trout (Oncorhynchus mykiss) and gilthead sea bream (Sparus aurata) cryopreserved sperm. Crybiology 50, 144-153.

Fowler HW. 1950. Os peixes de água doce do Brasil. Arquivos de Zoologia, 6, 333-340.

Gilbert W. 1991. Towards a Paradigm Shift in Biology. Nature, 349, 99.

Hamilton F. 1822. An account of the fishes found in the river Ganges and its Archibald Constable and Company, Edinburgh, UK.

Kimmel C, W Ballard, S Kimmel, B Ullmann, T Schilling. 1995. Stages of Embryonic development of the Zebrafish. Developmental dynamics 203, 253-310.
Luz RK, DA Reynalte-Tavaje, AA Ferreira, E Zaniboni-Filho. 2001. Desenvolvimento embrionário e estágios larvais do mandi-amarelo Pimelodus maculatus. B Inst Pesca, São Paulo 27, 49-55.

Morrison C, T Miyake, J Wright. 2001. Histological study of the development of the embryo and early larva of Oreochromis niloticus. J Morphol 247, 172-95.

Ninhaus-Silveira A, F Foresti, A de Azevedo. 2006. Structural and ultrastructural analysis of embryonic development of Prochilodus lineatus (Valenciennes, 1836) (Characifirme, Prochilodontidae). Zygote 14, 217-229.

Pezzato LE. 1997. O Estabelecimento das Exigências Nutricionais das Espécies Cultivadas. In: Simpósio sobre manejo e nutrição de peixes, Piracicaba, Brasil, Pp 45-60.

Romagosa E, MY Narahara, N Fenerichverani. 2001. Stages of embryonic development of the "matrinxã", Brycon cephalus (Pisces, Characidae). B Inst Pesca, São Paulo 27, 29-32.

Zilli L, R Schiavone, V Zonno, C Storelli, S Vilella. 2003. Evaluation of DNA damage in Dicentrarchus labras sperm following cryopreservation. Cryobiology 47, 227-235. 